\title{
A INDICAÇÃO GEOGRÁFICA (IG) SOB O PONTO DE VISTA GEOGRÁFICO PARA O QUEIJO DE COALHO DO AGRESTE DE PERNAMBUCO
}

\section{The geographical identification (GI) under geographic perspective for coalho cheese in agreste region of Pernambuco state}

\author{
Janieire Dorlamis Cordeiro Bezerra ${ }^{{ }^{*}}$, José Ribamar Silva do Nascimento Júnior ${ }^{1}$
}

\begin{abstract}
RESUMO
Este tema, indicação geográfica (IG), embora possua relação intrínseca com o espaço e a organização do mesmo, é pouco estudado na geografia. Para que a IG se torne ferramenta para promover o desenvolvimento territorial deverá esta ser atrelada a uma política não só econômica, mas social e ambiental, procurando atingir os produtores marginalizados, a fim de evitar sua exclusão social. A IG do queijo de coalho do Agreste de Pernambuco é de indicação de procedência (IP) a qual contribuirá nas mudanças espaciais. Até a obtenção da certificação, serão necessários estudos que contribuam na obtenção da IG. Após a certificação serão extremamente necessárias outras pesquisas para poder gerenciar o processo de certificação e inclusão da agricultura familiar, podendo assim concluir que a IG do queijo de coalho do Agreste de Pernambuco de fato incluiu o agricultor familiar, valorizando sua produção, melhorando sua renda e possibilitando ascensão. Portanto, a certificação trará, além do reconhecimento da região, uma mudança sócio-espacial, que envolverá futuramente estudos com indicadores socioeconômicos, apresentando a interação do homem com o território, a forma de apropriá-lo e utilizá-lo, contextualizando as modificações espaciais.
\end{abstract}

Palavras-chave: certificação, denominação de origem, indicação de procedência.

1 Universidade Federal da Paraíba, Programa de Doutorado Integrado em Zootecnia (PDIZ),Centro de Ciências Agrárias, Rodovia PB-079, 58397-000, Areia, PB, Brasil. E-mail: janieirebezerra@ hotmail.com

* Autor para correspondência.

Recebido / Received: 04/03/2016

Aprovado / Approved: 03/10/2016 


\begin{abstract}
This theme, geographic identification, although it has an intrinsic relationship with space and the organization of it, is little studied in Geography. For GI becomes tool to promote territorial development this should be linked to a policy not only economic but social and environmental, seeking to reach the marginalized producers in order to avoid social exclusion. GI coalho cheese Agreste of Pernambuco is indication of origin (IO) which will help in spatial changes. To obtain a certification studies will required to contribute to the achievement of the GI, and futher after certification further research will be extremely necessary in order to manage the certification process and inclusion of family farming. Therefore, it will possible to conclude that the coalho cheese GI Agreste Pernambuco in fact included the family farmer, enhancing production, improving their income and enabling the rise. Therefore, the certification will bring beyond recognition in the region, a socio-spatial change, which in the future will involve studies of socio-economic indicators, with the interaction of man with the territory, how to adopt it and use it, contextualizing the space changes.
\end{abstract}

Keywords: certification, designation of origin, origin indication.

\section{INTRODUÇÃO}

A indicação geográfica (IG) é um tema que possui relação intrínseca com o espaço e a organização do mesmo, no entanto, é pouco estudado na geografia brasileira (FALCADE, 2005). Sabe-se que o espaço na visão de Santos (1988) é uma realidade relacional entre a natureza e a sociedade, mediatizada pelo trabalho, onde o espaço é a concretude da ação social materializada na paisagem que se encontra em mutação constante. O autor salienta que as transformações do espaço são também as transformações da sociedade. Dessa forma, as transformações trazem diferenciações regionais que destacam determinado local, fazendo com que este tenha sua própria identidade.

Para a implantação de IG's, o Brasil se espelha nos modelos europeus principalmente na formulação de legislação apropriada com o intuito de agregação de valor aos produtos, geração de renda para os agricultores e aumento da competitividade de uma determinada região (PORTO, 2007). Porém, cabe atentar que a realidade do agricultor brasileiro é muito diferente dos europeus, cujas diferentes realidades fazem com que haja a necessidade de maiores estudos sobre o tema, sobretudo, de IG's específicas para os queijos, por exemplo.

É importante adaptar os mecanismos de implantação da IG para o Brasil, tendo em vista que muitas literaturas de embasamento para a implantação de IG são originárias da Europa, caso contrário as indicações geográficas não beneficiarão a produção agrícola familiar, nem tão pouco as famílias rurais à margem do mercado.

Na implantação das IG's o uso das geotecnologias se torna essencial para o processo de implantação, uma vez que estas trazem avanços significativos no desenvolvimento de pesquisas, ações de planejamento, gestão e manejo, e outros aspectos que se relacionam com a estrutura do espaço geográfico, usufruindo de geotecnologias como o Sistema de Informações Geográficas, técnicas e produtos de sensoriamento remoto, que garantem tomada de decisões mais consistentes sobre 
a padronização da produção (CAVALCANTE, 2010).

Há duas formas de IG segundo o Instituto Nacional da Propriedade Industrial (INPI, 2000) em sua Resolução n ${ }^{0} 75 / 2000$, Indicação de Procedência (IP) e a Denominação de Origem (DO). No caso da IG do queijo Coalho, do Agreste Pernambucano, consiste em IP, onde é preciso apenas que se comprove que a região se tornou conhecida por determinado produto, enquanto a DO apresenta critérios mais exigentes para a sua implementação, como a obrigatoriedade das características qualitativas do queijo ser de exclusividade do meio geográfico.

Identificar e valorizar recursos, privilegiando o desenvolvimento territorial, na ânsia de revalorização dos territórios e do meio rural (agricultura familiar) se mostra uma importante alternativa. Contudo, Velloso (2008), atenta para a importância de se buscar alternativas que promovam o desenvolvimento de oportunidades sociais, tanto no meio rural quanto no meio urbano, atentando ainda para o fato de que a simples implementação de uma indicação geográfica, desconsiderando o todo, o pode levar a caminhos bem opostos, ou seja, pode levar a sérios quadros de exclusão social.

Desta forma, para que a IG se torne ferramenta para promover o desenvolvimento territorial deverá estar atrelada a uma política não só econômica, mas social e ambiental, procurando atingir os produtores marginalizados, a fim de evitar sua exclusão social. Assim, a IG não deve ficar presa a um modelo padrão visto que cada região possui suas peculiaridades, então toda a diversidade local, cultural, econômica, ambiental e social deve ser levada em consideração.

Tendo em vista que a ideia de IG é uma possibilidade para valorizar os produtos agroalimentares advindos da pequena produção familiar, torna-se pertinente esclarecer a principal pergunta para investigação: A identificação geográfica do queijo de coalho do Agreste de Pernambuco poderá agregar valor à produção familiar? Hipoteticamente, tem-se que: a identificação geográfica contribui para o desenvolvimento regional, permitindo identificar e valorizar os recursos da região. A implantação da IG no AGRESTE de Pernambuco é para beneficiar a pequena produção com melhorias na qualidade de vida dos produtores. Portanto, objetivou-se com esta revisão de literatura analisar o processo de identificação geográfica do queijo de coalho e sua potencialidade de agregação de valor no contexto da pequena produção familiar do Agreste de Pernambuco.

\section{REFERENCIAL TEÓRICO}

\section{Espaço rural e agricultura familiar}

Pode-se compreender a agricultura familiar como sendo constituídas por pequenos e médios produtores e que os próprios componentes da família administram o empreendimento e dirigem todo o processo produtivo (PORTUGAL, 2004), podendo ou não contratar terceiros. Há um grande número de estabelecimentos no Brasil, cerca de 90\%, e $50 \%$ do número total de estabelecimento exclusivamente familiares estão localizados no Nordeste (KAGEYAMA et al., 2013).

Os produtos da agricultura familiar são diversificados e abastecem mais de $70 \%$ dos alimentos da mesa do consumidor (PORTAL BRASIL, 2015). Desta forma, o espaço rural é um universo heterogêneo que além da diversificação da produção de alimentos ainda há a criação de outras funções como as artesanais e comerciais, que geram uma apropriação simbólica do espaço, transformando o espaço e contribuindo para a manutenção do homem no campo.

\section{Histórico das IG's no mundo e no Brasil}

Um dos primeiros registros sobre IG 
é citado por Kakuta et al. (2006), em que a França tem importância histórica visto que este país instituiu um dos selos mais antigos referentes à qualidade dos alimentos que foi denominado de Apelação de Origem Controlada (AOC). No entanto, Soeiro (2005) afirma que Portugal seria pioneiro na IG por estabelecer legalmente o sistema de proteção da denominação de origem com o Vinho do Porto em 1756.

Para identificar se um determinado local tem potencial de IG é necessário averiguar, no mínimo, quatro pontos: quando um produto ou alimento tem em seu nome a região geográfica; quando este nome conquistou notoriedade por seus atributos; quando esta notoriedade advém de características regionais (solo, clima, vegetação, topografia); quando esta notoriedade advém da tradição dos produtores. Depois de averiguado as potencialidades para a obtenção de uma IG alguns passos até a sua aquisição devem ser seguidas, tais como; organização dos produtores da região em uma associação; levantamento histórico-cultural; construção de um regulamento técnico; criação de um conselho regulador; e encaminhar a solicitação de reconhecimento ao INPI (INPI, 2000).

A Europa se destaca em termos de IG's agropecuários possuindo certificações em diversos produtos como vinhos, frutas, óleos, queijos, embutidos, mel, carnes, cervejas, cereais, água mineral, dentre outros (FALCADE, 2005). Para se ter uma ideia, as certificações concedidas mundialmente só para vinhos gira em torno de 900 certificações, sendo que cerca de $96 \%$ dessas certificações se concentram na Europa (FALCADE, 2005). Já para os queijos europeus existem mais de 2 mil certificações (NORÕES, 2009). Na França, podem ser citados os exemplos de certificação o Champagne, os vinhos tintos de Bourdeaux, os queijos das regiões de Roquefort, Comté, Cantal e Camembert, o Cogna e na Itália o presunto de Parma e os queijos Parmigiano Reggiano e Grana Padano.

Para garantir a veracidade do produto e a segurança alimentar a União Europeia criou os sistemas de proteção e valorização dos produtos agroalimentares. São eles: DOP - denominação de origem protegida; IGP - indicação geográfica protegida; ETG especialidade tradicional garantida.

A DOP identifica um produto como originário de um determinado local ou região, a relação com a área geográfica é essencial ou exclusiva para a qualidade ou as características do produto, tem-se como exemplo a castanha da Padrela e queijo Serra da Estrela (Portugal). A IGP identifica um produto da mesma forma que a DOP e a relação com a área geográfica é essencial para uma qualidade determinada ou a reputação ou outra característica do produto, podendo-se citar salpicão de Vinhais e a cereja da Cova da Beira (Portugal). As diferenças entre elas, além da maior restrição da primeira, se referem à produção, transformação e processamento que na DOP é realizado na mesma área geográfica e no IGP não é obrigatório que todas as fases sejam realizadas na mesma área geográfica. A ETG é utilizada tradicionalmente ou identifica o caráter tradicional do produto é sem relação à área geográfica ou a uma área delimitada e não há limites na origem da matéria prima, ou seja, a proteção e no nome do produto, Tem-se como exemplos a alheira de Mirandela e frutos em vinho do Porto, em Portugal (SANTOS, 2013; RUIVO, 2014; VALES, 2014).

No Brasil a IG ainda caminha a passos lentos, embora já se ressalte algumas identificações como os vinhos do Vale dos Vinhedos em 2002 (primeira certificação), o Café do Cerrado Mineiro certificado em 2005 (segunda certificação), Carne do Pampa Gaúcho em 2006 (terceira certificação) e Cachaça de Parati-RJ em 2007 (quarta certificação). Ressalta-se também que são poucos 
os certificados de IG brasileiros, existem 16 produtos agropecuários certificados como Indicação de Procedência e quatro Denominações de Origem (YOKOBATAKE et al., 2013).

Desta forma, para a implantação de IG's, o Brasil se espelha nos modelos europeus principalmente a formulação de legislação apropriada com o intuito de agregação de valor aos produtos, geração de renda para os agricultores e aumento da competitividade de uma determinada região (PORTO, 2007). Porém, cabe atentar que a realidade do agricultor brasileiro é muito diferente dos europeus, cujas diferentes realidades fazem com que haja a necessidade de maiores estudos sobre o tema, sobretudo, de IG's específicas para queijos.

Nessa percepção, Santos (1988) relata que nos países europeus a personalidade de cada região se construiu em longo prazo e evolutivamente, cristalizando os traços do passado. Algo que na prática pode ser observado na delimitação de uma região e os motivos pelos quais algumas áreas são incluídas e outras, embora próximas, não são na $\mathrm{IG}$, devido à relação dos fatores naturais e humanos, ou seja, da cristalização do passado. Assim, os critérios para delimitação foram estabelecidos ao longo do tempo.

Algumas IG's potenciais surgem no Brasil em estados como Minas Gerais (Cachaça de Salinas, Queijo da Serra da Canastra, Café da Serra do Caparaó), Santa Catarina (Maçã de São Joaquim, Vinho Goethe - Urussanga, Queijo Serrano), Rio Grande do Sul (Doces de Pelotas, Chocolates de Gramado), Amazonas (Açaí de Codejas), Amapá (Mel de Bailique), Bahia (Cachaça de Abaíra), e Mato Grosso do Sul (Linguiça de Maracajú).

Além do queijo de coalho de Pernambuco, outros queijos também estão na busca de certificação no Nordeste como os queijos do Seridó Potiguar e o da região do Jaguaribe no Ceará (SEBRAE, 2007), que embora sejam denominados de queijos de coalho, cada um carrega diferenças que poderão ser comprovadas a nível molecular, demonstrando que as características da região interferem nas características do produto (NORÕES, 2009). Os três queijos Nordestinos receberão a denominação de queijo de coalho, o que os distinguirá será o local (queijo de coalho do agreste de Pernambuco, queijo de coalho da região do Jaguaribe, etc.). Dessa forma, o selo de indicação geográfica dos queijos de coalhos ficarão sob exclusividade da região nordestina e com isso nenhum outro, embora similar, poderia usar o nome queijo de coalho para comercialização (SEBRAE, 2010).

\section{Implicações das IG's no território}

Durante muitos anos os produtos "artesanais", "produtos da terra", ou "produtos com história" foram sinônimos de atraso socioeconômico e de falta de segurança alimentar, sobretudo, em tempos de globalização. Todavia, o resgate da identidade sociocultural, por meio da valorização dos produtos artesanais, torna-se uma saída para a comercialização do produto, divulgando a identidade cultural e dando melhores condições para a permanência do homem no campo, sendo que os mecanismos de valorização consistem em referenciar as tradições, localidade, origem e prestígio. Assim, o artefato cultural (o queijo de coalho), interage com cinco processos culturais distintos (representação, identidade, produção, consumo e regulação), cujas diferentes interações resultarão diversas respostas (ALMEIDA et al., 2011).

Os mesmos autores ainda publicaram uma tradução em português do diagrama de Du Gay et. al (1997) com os cinco processos culturais e concluíram que "o significado não deriva diretamente do objeto, mas da articulação dos cinco momentos do processo que juntos estabelecem um espaço cultural no qual o significado é criado, modificado e 
recriado" (ALMEIDA et al., 2011). Assim, o significado do produto cultural é dinâmico e se propaga nas diversas situações, promovendo a sua circulação.

Vargas (2008, p. 8.) ao analisar o perfil do mercado atual relata a seguinte tendência:

A tendência pela busca por referenciais de origem dos produtos alimentícios por parte dos consumidores pode tornar-se um importante critério de valorização dos mesmos, devido à influência na percepção de qualidade e de segurança. Esta busca pela origem motiva o estabelecimento de mecanismos para valorização e garantia de qualidade diferenciada para estes produtos, referenciando aspectos geográficos ou com reputação tradicional, com o objetivo de diferenciar a produção local, agregando valor à mesma e posicionando-a em nichos especificos de mercado. Estes mecanismos de proteção geográfica, a saber, as indicações de procedência (IP) e as denominações de origem (DO), buscam valorizar territórios e seus produtos, vinculando-os com o local de origem.

Percebe-se, assim, uma nova possibilidade de mercado para a pequena produção. Mas é importante adaptar os mecanismos de implantação da IG para a região, tendo em vista que muitas literaturas de embasamento para a implantação de IG são originárias da Europa, caso contrário às indicações geográficas não beneficiarão a produção agrícola familiar, nem tão pouco as famílias rurais à margem do mercado.

Identificar e valorizar recursos, privilegiando o desenvolvimento territorial, na ânsia de revalorização dos territórios e do meio rural (agricultura familiar) se mostra uma importante alternativa em direção ao desenvolvimento territorial. Contudo, Velloso (2008, p. 21.), atenta para a importância de se buscar alternativas que promovam o desenvolvimento de oportunidades sociais, tanto no meio rural quanto no meio urbano, refletindo, sobretudo quando afirma que:

A agregação de valor ao produto, mesmo buscando integrar a parcela pobre no meio rural, causaria maior exclusão do que integração, pois a outra parcela da pobreza (no meio urbano, que é bem maior) não mais teria condições para adquirir os produtos daquela agricultura [...].

A mesma autora alerta sobre a importância de que o simples fato de implementação de uma indicação geográfica, desconsiderando o todo - a complexidade -, pode levar a caminhos bem opostos, ou seja, pode levar a sérios quadros de exclusão social. Desta forma, para que a IG se torne ferramenta para promover o desenvolvimento territorial deverá estar atrelada a uma política não só econômica, mas social e ambiental, procurando atingir mesmo os produtores marginalizados, a fim de evitar sua exclusão social. Assim, a IG não deve ficar presa a um modelo padrão visto que cada região possui suas peculiaridades, então toda a diversidade local, cultural, econômica, ambiental e social deve ser levada em consideração.

\section{Produção de leite em Pernambuco}

Em Pernambuco está inserida uma das maiores bacias leiteiras do Nordeste (segunda maior do Nordeste e a oitava maior do Brasil), com mais de 663 milhões de litros que representa $19,7 \%$ e $2,5 \%$ do leite produzindo no Nordeste e no Brasil, respectivamente, destacando o estado com um crescimento de cerca de $173 \%$ no quantitativo de leite produzido (só o município de Pedra cresceu cerca de 576\%) em dez anos (1998-2008), dos quais $52 \%$ da produção se destina aos laticínios, cabendo ressaltar que o consumo de leite e derivados do estado é maior (63\%) nas famílias de baixa renda (IBGE, 2007; SEBRAE, 2010). 
A bacia leiteira é formada por $44 \mathrm{mu}-$ nicípios (Figura 1) e por cerca de 10.000 produtores, abrangendo uma área de $20.278 \mathrm{Km}^{2}$, produzindo em média 2,2 milhões de litros de leite, sendo basicamente a metade do leite produzido destinado ao fabrico de queijos. A representatividade dessa bacia no PIB pernambucano de cerca de R 1 bilhão e por mês Pernambuco movimenta aproximadamente R\$ 81 milhões com a comercialização de leite, cabendo ressaltar que os pernambucanos são os maiores consumidores de queijo do nordeste (DIÁRIO DE PERNAMBUCO, 2012; PAQUEREAU, 2010).

Conforme dados do IBGE (2010) os três municípios mais produtores de leite são, respectivamente: Itaíba, Buíque e Pedra, sendo que a região do Agreste beneficia cerca de $75 \%$ do leite produzido. O município de Itaíba se destaca também no âmbito nacional, sendo o $11^{\circ}$ maior produtor de leite do Brasil (IBGE, 2011). No caso de Jucati (Figura 1 - linha vermelha), possui 7.498 bovinos leiteiros, 1.568 vacas em lactação e uma produção de 2 mil litros/dia (IBGE, 2009). Além desses fatores, o município é caracterizado como rural ( $73 \%$ da população), com rendimento total mensal de R\$192,00 e PIB agropecuário de 28\% (IBGE, 2010). Dessa forma, a prática leiteira e queijeira nessa região é uma atividade que garante a permanência do homem no campo, contudo, é uma atividade mal remunerada, necessitando de pesquisas desenvolvimentistas que possam gerar melhorias no rendimento da produção familiar.

\section{Análise da IG para o queijo de coalho do agreste de Pernambuco}

A identificação geográfica como agregador de valor aos produtos de origem agropecuários não é algo recente, embora nos últimos anos tenha se dado maior ênfase a esta prática, sobretudo aos produtos vindos da agricultura familiar. De forma geral, a indicação geográfica (IG) pode ser conceituada como sendo a indicação de um produto ou serviço como originário de um local, região ou país, quando determinada reputação, característica e/ou qualidade possam ser vinculadas essencialmente a esta sua origem particular (BRASIL, 2011).

Para Glass; Castro (2009), a IG é definida como uma ferramenta coletiva de promoção mercadológica na qual os lugares, pessoas e produtos são destacados, enfatizando sua herança histórico-cultural que, desta forma, geram um mecanismos mercadológico exclusivo, na qual a IG atua como uma espécie de certificação, corroborando com Cruz et al. (2012), no qual a IG correlaciona determinado produto as características especiais em suas dimensões geográficas e histórico-culturais as quais possuem forte apelo mercadológico e, assim, dá condições para a geração de emprego e renda. Desta forma, a IG pode auxiliar no crescimento econômico local, contribuindo para uma divisão de renda mais humanitária, sobretudo em países mais pobres ou emergentes (PEDREIRA, 2007).

No processo de IG as relações entre as condições ambientais e as características do produto, estão fortemente relacionadas, visto que as condições geográficas locais, principalmente do clima e do solo, impregnam-se nas características físico-químicas do produto, tornando-o a expressão do meio geográfico (FALCADE, 2005). Assim, a IG é uma expressão das condições ambientais e sociais do local onde foram produzidos.

Para se entender os processos para um IG, são necessários analisar duas formas que dão condições de registro, segundo o Instituto Nacional da Propriedade Industrial (INPI, 2000) em sua Resolução nº. 75/2000, Indicação de Procedência (IP) e a Denominação de Origem (DO). As duas vertentes para IG são assim definidas pelos Artigos 177 e 178 da Lei: 


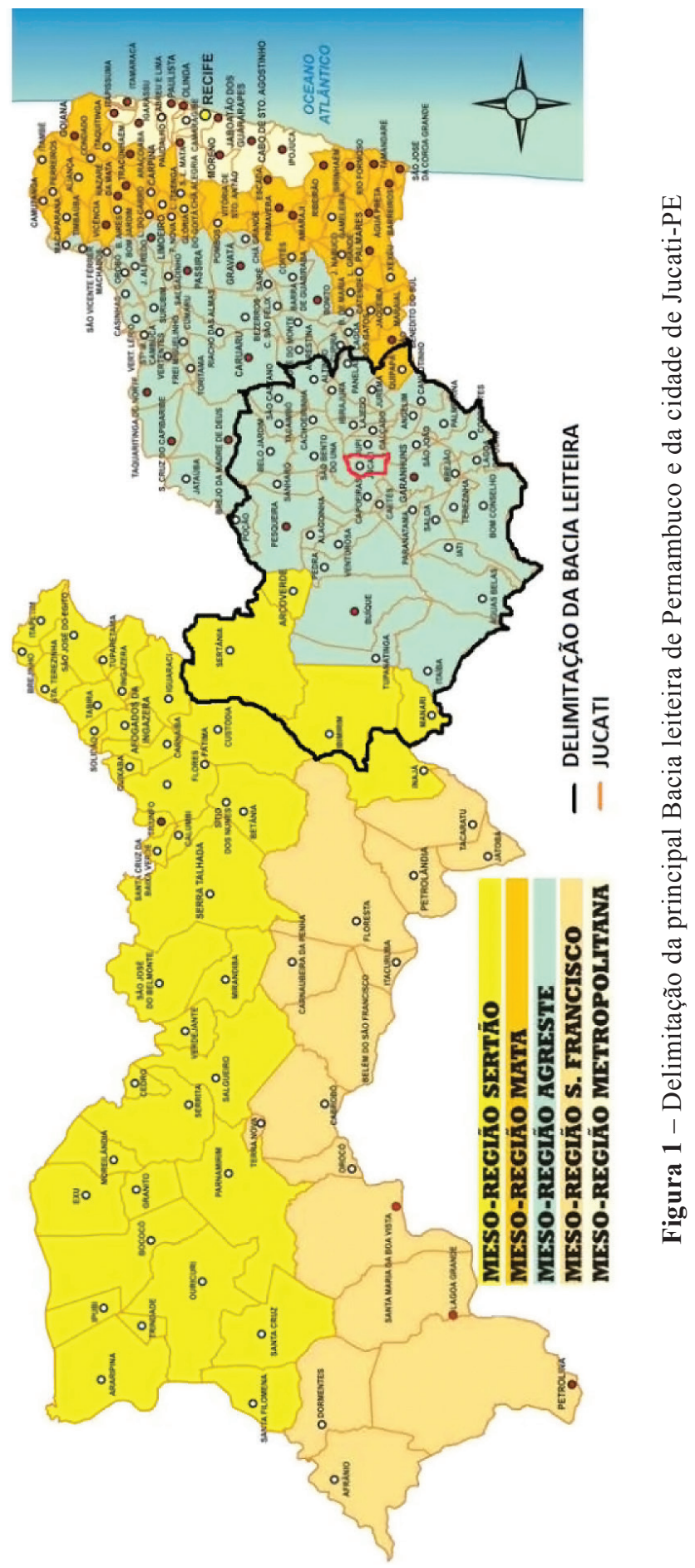


Art. 177 - Indicação de procedência é o nome geográfico de um país, cidade, região ou uma localidade de seu território, que se tornou conhecida como centro de produção, fabricação ou extração de determinado produto ou prestação de determinado serviço.

Art. 178 - Denominação de origem é o nome geográfico de país, cidade, região ou localidade de seu território, que designe produto ou serviço cujas qualidades ou características se devam exclusiva ou essencialmente ao meio geográfico, incluidos fatores naturais e humanos.

A IG do queijo de coalho do Agreste de Pernambuco é de indicação de procedência (IP) a qual contribuirá nas mudanças espaciais. Desta forma, as conceituações de espaço e território tornam pertinentes para o entendimento deste processo, uma vez que a IG possui uma relação intrínseca com o espaço, bem como da organização espacial. Sendo assim, o espaço geográfico é o objeto de estudo da geografia, no qual Santos (1988) conceitua o espaço como uma realidade relacional entre a natureza e a sociedade concebidas por meio do trabalho, em que a sociedade é transformada em espaço, visto que a mesma está embutida nas formas geográficas.

Com esta perspectiva, observa-se que o espaço é fruto das ações humanas sobre o próprio espaço, sendo tanto a condição como o resultado. Logo, uma implantação de uma IG contribui para a valorização e a significação diferenciada do espaço. Neste sentido, Lacoste (1977) salienta da importância estratégica das diferenciações geográficas, considerando-as fundamentais, visto que a mudança no papel territorial gera novos valores sociais e econômicos.

Um método de abordagem do espaço se dá por meio das reflexões da questão regional. A região pode influenciar de tal maneira que poderá afetar em escala global e isso se dá, sobretudo, devido à globalização. Contudo, o modo de produção se especializa regionalmente, contribuindo para a construção de espaços regionais (SANTOS, 1988). Falcade (2005) aborda que a região está contida de significados representacionais em que a sociedade se identifica, se comunica e exerce seu poder, portanto, trata-se do espaço vivido. Assim a origem de um produto passa a ser reconhecida mundialmente como fator de identidade, associando-o a qualidade, a cultura e a história, sendo que esses intimamente ligados ao espaço definido e delimitado, ou seja, no caso em estudo, ao agreste meridional pernambucano.

Desta forma, a implementação de uma IG, conforme Falcade (2005) é uma necessidade social ligada a fatores políticos, econômicos, ambientais e do próprio $\mathrm{Eu}$ social, que gera um estabelecimento de uma regionalização que pode estar delimitado por uma DO ou uma IP. Os objetivos de uma IG é gerar promoção comercial, garantir autenticidade, agregar valor, promover o desenvolvimento regional, preservar a biodiversidade, o conhecimento tradicional e os recursos naturais.

A certificação com base na IG possibilitará o reconhecimento e a valorização da região podendo fomentar o segmento turístico. Além do reconhecimento da região, possibilitará uma mudança sócio-espacial, que envolverá futuramente estudos com indicadores socioeconômicos, apresentando a interação do homem com o território, a forma de apropriá-lo e utilizá-lo, contextualizando as modificações espaciais.

Até a obtenção da certificação, serão necessários estudos que contribuam na obtenção da IG, e outras pesquisas após a certificação serão extremamente necessárias para poder gerenciar o processo de certificação e inclusão da agricultura familiar, podendo assim concluir que a IG do queijo de coalho do Agreste de Pernambuco de fato incluiu o 
agricultor familiar, valorizando sua produção, melhorando sua renda e possibilitando ascensão, uma vez que a região possui grandes carências em educação, saúde, saneamento, habitação e meio ambiente, na qual Almeida et al. (2011), salientam a relevância econômica e social da produção de queijo de coalho, principalmente da produção dos pequenos produtores.

\section{CONSIDERAÇÕES FINAIS}

A certificação do queijo de coalho do Agreste de Pernambuco trará, além do reconhecimento da região, uma mudança sócio-espacial, que envolverá futuramente estudos com indicadores socioeconômicos, apresentando a interação do homem com o território, a forma de apropriá-lo e utilizá-lo, contextualizando as modificações espaciais.

\section{REFERÊNCIAS}

ALMEIDA, S. L.; GUERRA, J. R. F.; PAIVA JUNIOR, F. G. A representação do Queijo Coalho no Contexto da Indicação Geográfica: uma Análise do Documentário Coalho, um Queijo Pernambucano. In: Encontro de Estudos Multidisciplinares em Cultura, 7, 2011, Salvador. Anais... Salvador, 2011.

BRASIL. Pecuária e Abastecimento. Indicação Geográfica (IG). Disponível em: <http:// www.agricultura.gov.br>. Acesso em: 28 mar. 2011.

CAVAlCANTE, G. S. et al. Aplicação de geotecnologias como subsídio ao gerenciamento das unidades produtoras de queijo coalho artesanal no município de Morada Nova - Ceará. In: Reunião anual da SBPC, 62, 2010, Natal, Anais... Natal, 2010.

CRUZ, M. C. et al. Análise de pedidos de identificações geográficas para definição de critérios que possam contribuir para a competitividade do agronegócio brasileiro. Disponível em: $<$ http://www.cnpma. embrapa.br/boaspraticas/download/Analise Pedidosindicaçãogeograficas.pd f>. Acesso em: 20 abr. 2012.

DIÁRIO DE PERNAMBUCO. Produção leiteira do agreste pernambucano entra em debate (2012). Disponível em: <www. old.diariodepernambuco.com.br/nota. asp? materia $=20120413114210>$ Acesso em: 06 out. 2012.

DU GAY, P. et al. Doing Cultural Studies: The Story of the Sony Walkman, Londres: Sage Publications, 1997. 175 p.

FALCADE, I. Indicações geográficas: o caso da região com indicação de procedência Vale dos Vinhedos. 2005. 190 p. Dissertação (Mestrado em Geografia) - Universidade Federal do Rio Grande do Sul, Porto Alegre, 2005.

GLASS, R. F; CASTRO, A. M. G. As indicações geográficas como estratégia mercadológica para vinhos. Brasília, DF: Embrapa Informação Tecnológica, 2009. 113p.

INSTITUTO BRASILEIRO DE GEOGRAFIA E ESTATÍSTICA (IBGE). Censo Agropecuário 2007. Brasil, 2007. Disponível em: $<$ http://www.ibge.gov.br>. Acesso em: 11 out. 2012 .

INSTITUTO BRASILEIRO DE GEOGRAFIA E ESTATÍSTICA (IBGE). Cidades: Indicadores econômicos do município de Jucati-PE. Brasil, 2009. Disponível em: $<$ http://www.ibge.gov.br>. Acesso em: 11 out. 2012.

INSTITUTO BRASILEIRO DE GEOGRAFIA E ESTATÍSTICA (IBGE). Pesquisa da 
pecuária municipal. Brasil, 2010. Disponível em: <http://www.ibge.gov.br>. Acesso em: 11 out. 2012.

INSTITUTO BRASILEIRO DE GEOGRAFIA E ESTATÍSTICA (IBGE). Ranking da produção leiteira de Pernambuco em 2011 [2011]. Disponível em: <http://www.ibge.gov. br>. Acesso em: 11 out. 2012.

INPI. Instituto Nacional de Propriedade Industrial (Brasil). Resolução INPI 075, de 28 de novembro de 2000. Disponível em: <http://www.inpi.gov.br/menuesquerdo/ indicação/legislação/resolução $>$. Acesso em: 26 jul. 2010.

KAGEYAMA, A. A. Uma tipologia dos estabelecimentos agropecuários do Brasil a partir do censo de 2006. Revista de Economia e Sociologia Rural, v. 51, n. 1, p. 105-122, 2013.

KAKUTA, S. M. et al., Indicações geográficas: guia de respostas. Porto Alegre: SEBRAE/RS, 2006.

LACOSTE, Y. A geografia serve antes de mais nada para fazer a guerra. Campinas: Papiros, 1977. 263p.

\section{NORÕES. C. Evento discute indicação} geográfica de queijo de coalho nordestino. 2009. Disponível em: <http://www.embrapa. br/imprensa/noticias/2009/novembro/3asemana/evento-discute-indicacao-geograficade-queijo-de-coalho-nordestino/>. Acesso em: 29 maio 2012.

PAQUEREAU, B. P. D. Construção de indicação geográfica - IP para o queijo de coalho do agreste de Pernambuco (2010). Disponível em: <http://eventos.uece.br/ siseventos/processaEvento/evento/downloadArquivo.jsf?id=23\&diretorio=documento
s\&nomeArquivo=23-30112011-082009.pdf $\&$ contexto $=$ simposiodequeijos $>$. Acesso em: 25 nov. 2011.

PEDREIRA, R. B. In: Simpósio Internacional de Indicações Geográficas, 1., 2007, Beijing. Anais eletrônicos... Disponível em: $<$ http://raulbittencourt.multiply.com/journal/ item/70>. Acesso em: 28 de mar. 2012.

PORTO, P. C. R. Indicações geográficas. A proteção adequada deste instituto jurídico visando o interesse público nacional. 2007. 135p. Monografia (Programa de pósgraduação da Faculdade de Direito) - Universidade do Estado do Rio de Janeiro, Rio de Janeiro, 2007.

PORTAL BRASIL. Agricultura familiar produz $\mathbf{7 0} \%$ dos alimentos consumidos por brasileiro. Disponível em: $<$ http://www. brasil.gov.br/economia-e-emprego/2015/07/ agricultura-familiar-produz-70-dosalimentos-consumidos-por-brasileiro $>$. Acesso em: 01 ago. 2016.

PORTUGAL, A. D. O desafio da agricultura familiar. 2004. Disponível em; <http:// www.embrapa.br/imprensa/artigos/2002/ artigo.2004-12-07.2590963189/>. Acesso em: 20 nov. 2012.

RUIVO, J. F. L. Determinantes da Criação de Valor no Pão Tradicional Alentejano. Évora: Universidade de Évora - Escola de Ciências Sociais. 2014. 114p. Dissertação (Mestrado em Economia e Gestão Aplicadas da Universidade de Évora) - Escola de Ciências Sociais, Évora, 2014.

SANTOS, M. Metamorfose do espaço Habitado. São Paulo: HUCITEC, 1988. 122p.

SANTOS, M. S. S. Avaliação de conformidade da rotulagem de géneros alimentícios 
de um estabelecimento de venda a retalho. 2013. 121p. Dissertação (Mestrado Integrado em Medicina Veterinária da Universidade de Lisboa) - Universidade de Lisboa, Lisboa, 2013.

SEBRAE. Um queijo pernambucano com nome e sobrenome. In: SEBRAE agronegócios. n. 1. Brasilia-DF. 2007.

SEBRAE. Boletim setorial do agronegócio-Bovinocultura leiteira (2010). Disponível em: <http://www.sebrae.com.br/setor/ leite-e-derivados/Boletim\%20Bovinocultura. pdf $>$. Acesso em: 06 jun. 2011.

SOEIRO, A. Denominações de origem e indicações geográficas protegidas: a sua importância. 2005. Disponível em: $<$ http:// www.pluridoc.com/Site/FrontOffice $>$. Acesso em: 15 abr. 2012.

VALES, D. L. Contributo para a valorização e proteção dos Produtos tradicionais açorianos. 2014. 236p. Dissertação (Mestrado em Tecnologia e Segurança Alimentar)
- Universidade dos Açores, Ponta Delgada, 2014.

VARGAS, I. C. F. Indicações Geográficas no Brasil: Possibilidades para os produtores inseridos na área de proteção ambiental do Ibirapuitã-RS. 2008. 116p. Dissertação (Mestrado em Extensão Rural) - Universidade Federal de Santa Maria: UFSM, Santa Maria, 2008.

VELLOSO, C. Q. Indicação Geográfica e desenvolvimento territorial sustentável: A atuação dos atores sociais na dinâmica de desenvolvimento territorial a partir da ligação do produto ao território (um estudo de caso em Urussanga, SC). 2008. 168p. Dissertação (Mestrado em Agroecologia) - Universidade Federal de Santa Catarina, Florianópolis, 2008.

YOKOBATAKE, K. L. A. Denominação de origem e indicação geográfica de produtos agrícolas. Periódico Eletrônico Fórum Ambiental da Alta Paulista, v. 9, n. 7, 2013. 